\title{
THE EFFECT OF DIETHYLSTILBESTROL ON THE CALCIUM, PHOSPHORUS AND NITROGEN METABOLISM OF PROSTATIC CARCINOMA ${ }^{1}$
}

\author{
By ALBERT SCHILLING ${ }^{2}$ and DANIEL LASZLO with THE ASSISTANCE of JUDITH \\ BELLIN AND ESTELLE D. GOTTESMAN
}

\author{
(From the Division of Neoplastic Diseases, Montefiore Hospital, New York)
}

(Submitted for publication January 21, 1950; accepted, March 27, 1950)

This report deals with a metabolic study on a patient with diffuse osseous metastases secondary to carcinoma of the prostate gland. The patient was studied before treatment and during the first four months of estrogen therapy.

The clinical course and the chemical, roentgenological and pathological findings in prostatic carcinoma have been extensively documented in the medical literature $(1,2)$. Since the fundamental work of Huggins and co-workers (3-5) the effects of castration and female sex hormone medication have been repeatedly described $(1,6,7)$. However, to our knowledge, there have not been any reports of an evaluation of the mineral and protein metabolism of patients with this disease, nor of the effects of therapy on calcium, phosphorus and nitrogen metabolism. ${ }^{3}$

\section{CASE REPORT}

\section{History}

The patient M.B. (M.H. 47872), age 69, was admitted to Montefiore Hospital May 1949. He had been an operator in a garment factory and had worked until several months prior to hospitalization. His diet and habits were good, and his past medical history was uneventful. The symptoms of his present illness began with low back pain in April 1948. He consulted an orthopedic surgeon in June 1948 and X-rays were taken. Bone biopsy was advised, but the patient refused the procedure. In September 1948, he noticed a tender lump in the right lower portion of his back. He entered another hospital in November 1948, and a mass was excised from the right

1 This project has been supported in part by a grant from The American Cancer Society and by a cancer control grant from the National Cancer Institute of the National Institutes of Health, U. S. Public Health Service.

2 Trainee, National Cancer Institute.

${ }^{3}$ In a paper presented at the 38th annual meeting of the American Association for Cancer Research, Aub, Tibbets and Nathanson reported on the metabolic effects of treatment of carcinoma of the prostate (16). We are grateful to these authors for furnishing us with their unpublished data which are in agreement with our findings. sacro-iliac region. The pathological report was metastatic adenocarcinoma, probably of prostatic origin. The patient then received a total of 10 injections of female hormone, type and dosage not known. In January 1949, radiotherapy was administered, 2000r, to the lumbar spine, and $2000 \mathrm{r}$ to each of four pelvic portals. He received no further therapy until admission to this hospital. Since December 1948, he had been complaining of increased low back pain, intermittent leg cramps and frequency of urination. The therapy did not relieve these symptoms.

\section{Physical examination}

The patient was a well nourished and well developed elderly male who was ambulatory and in no apparent distress. There was full range of motion in all extremities without pain, and the only area of tenderness elicited was in the right sacro-iliac region where a well-healed incisional scar was noted. The lung fields were normal. The heart was not enlarged, the sounds were of good quality, the rhythm and rate were normal, and murmurs were not heard. The blood pressure was $125 / 70$. The abdomen did not reveal any tenderness, rigidity, distension or masses; the liver, kidneys, and spleen were not palpable. The testicles felt normal to palpation. Rectal examination revealed a normal-sized, nodular, irregular and rather firm prostate. Many small, hard nodules were felt extending from the prostate into the perirectal tissue.

\section{Laboratory data}

Temperature, pulse and respiration remained within normal limits throughout the hospital stay. The weight varied between 67.4 and 62.8 kilograms (Table I). The urine was clear, yellow, acid in reaction with a specific gravity ranging between 1.010 and 1.026 in various samples, and was negative for sugar, albumin, blood and casts. The red blood count varied between $3,720,000$ and $4,200,000$. The hemoglobin varied between 10.5 and 12.0 grams. The white blood count varied between 3,850 and 7,050 with a normal differential except for a persistent eosinophilia ranging between $4 \%$ and $13 \%$. Blood Mazzini test was negative. The fasting blood sugar was 97 mg.\%. The total proteins of the serum were 5.2 grams $\%$, with an albumin/globulin ratio of 4.1/1.1. The blood urea nitrogen ranged between 13.5 and $17.3 \mathrm{mg} . \%$. A urea clearance test revealed minimal clearances of $25 \%$ and $32 \%$ of normal. On admission, the serum calcium was $9.8 \mathrm{mg} . \%$, serum phosphorus $3.1 \mathrm{mg} . \%$, serum alkaline phosphatase 3.1 Bodansky Units (B.U.) and serum acid 


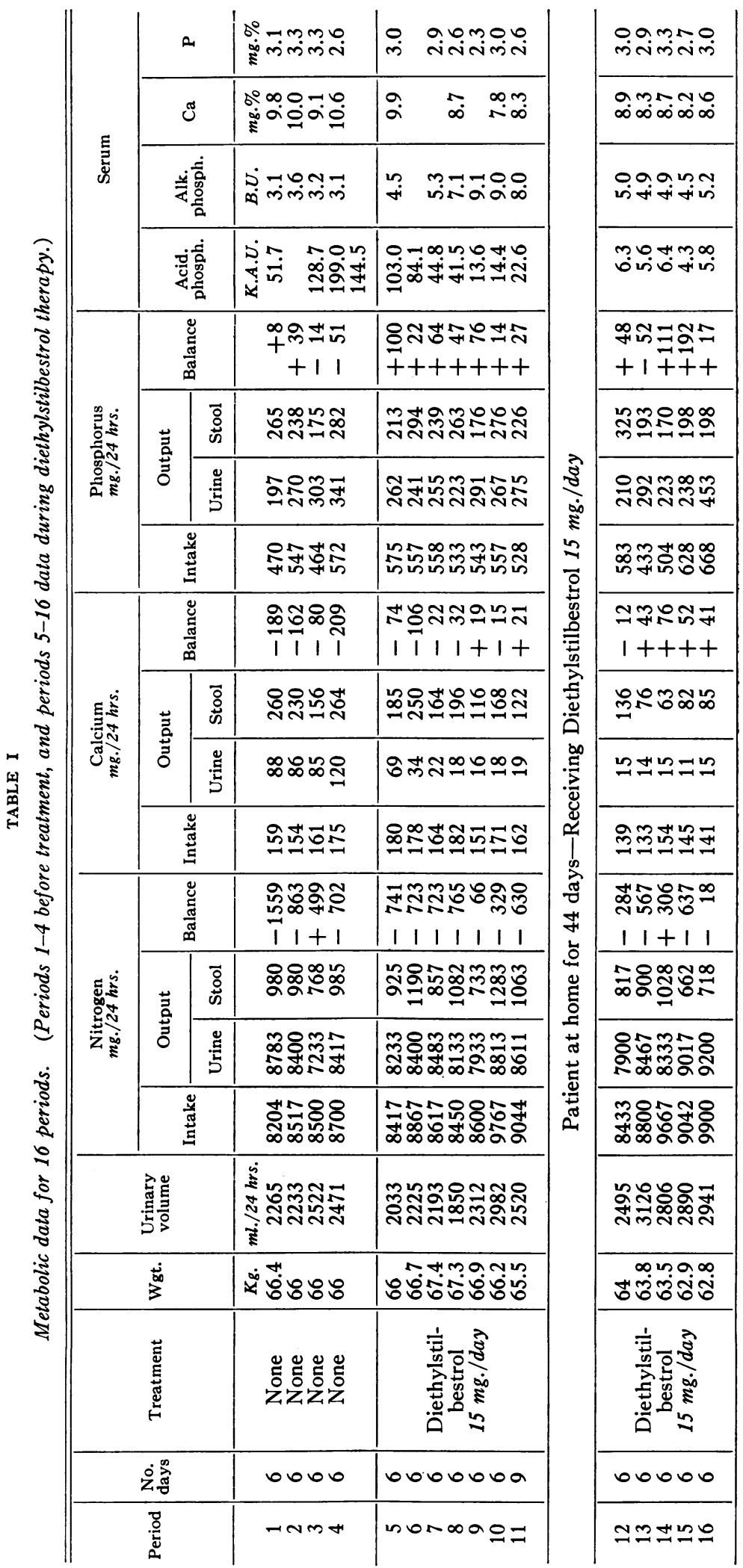


phosphatase 51.7 King-Armstrong Units (K.A.U.). The subsequent blood-chemical values are listed in Table I.

An electrocardiogram showed left axis deviation. In May, June, July and September, 1949, roentgenograms were taken of the skull, chest, pelvis, thoracic spine, lumbosacral spine and both femora. The pelvis showed widespread areas of increased sclerosis (Figure 1). The spine showed increased sclerosis in several vertebrae. There was no evidence of metastases to the skull and femora. The chest showed thickened pleura at the left base, but there was no evidence of pulmonary metastasis. Osteoblastic changes were noted in the right seventh and ninth ribs. Comparison of the roentgenograms from the period of May to September did not reveal any significant changes.

\section{Course in hospital}

After five days of preliminary investigation, the patient entered the metabolic ward and was studied for 69 days. The studies were then interrupted for 44 days and resumed for an additional 30 days.

The patient was ambulatory during the entire period of investigation. His appetite was good and he did not reject any food during the entire study. Initially, there was moderate low back pain which occasionally required codeine, grains $1 / 2$, for relief. After 24 days of study prior to treatment, intramuscular diethylstilbestrol therapy, $5 \mathrm{mg}$. three times a day, was instituted. The back pain subsided completely after a month and did not recur. Two weeks after initiating estrogen therapy, minimal ankle edema was noted which lasted for two weeks and then subsided.

After 69 days of metabolic studies the patient went home for 44 days, still receiving diethylstilbestrol $15 \mathrm{mg}$. daily. He was then readmitted for further study. At that time, physical examination revealed findings similar to those of the first examination, with the following exceptions: Moderate bilateral gynecomastia was present. There was sparse axillary hair, normal male-type chest hair and female distribution of supra-pubic hair. The testes felt markedly atrophic to palpation. Palpation of the prostate revealed findings similar to those of the first admission. Lumbosacral tenderness was not present.

Metabolic studies were resumed for an additional 30 days. During the entire period, the patient was ambulatory and did not have any pain. He was discharged October 1949, and has been seen regularly in the OutPatient Clinic. He continues to receive diethylstilbestrol $15 \mathrm{mg}$. daily, and to date has remained well, without complaints.

\section{METHODS}

The methods employed were described in a previous paper (8). During the entire period of study, the patient received a low calcium diet $(9,10)$ containing a daily average of 1946 calories (61 grams protein, 66 grams fat, and 277 grams carbohydrate). Three menus were alternated during each six day period.

Aliquots of every food served were analyzed for calcium, phosphorus and nitrogen. Aliquots of the pooled urine and pooled feces of each six day period were similarly analyzed. Blood analyses were performed at frequent intervals for calcium, phosphorus, alkaline phosphatase, acid phosphatase and urea nitrogen. Body weight, fluid intake, urine volume and urinary creatinine were determined daily.

\section{RESULTS}

The metabolic data and serum values are given in Table I and Figure 2. The metabolic balances are summarized in Table II.

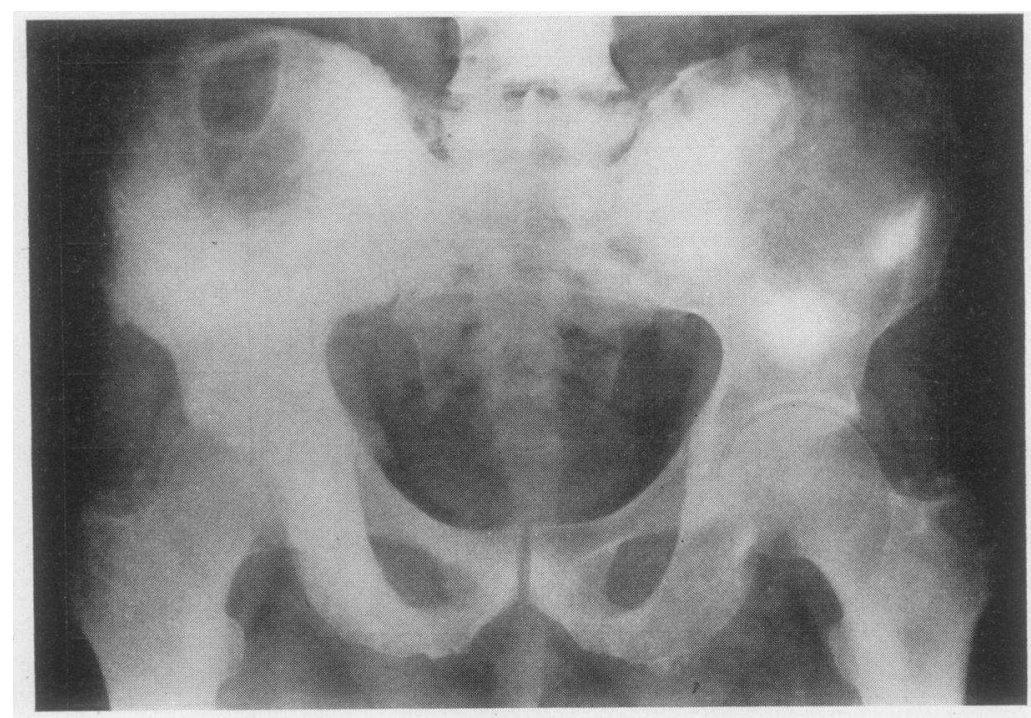

Fig. 1. Roentgenogram of the Pelvis Showing Widespread PredomiNantly Osteoblastic Metastases 
TABLE II

Average nitrogen, calcium, phosphorus and theoretical phosphorus balances, expressed in mg./24 hours

The first phase represents the average values in the 24 days before treatment. The following three phases represent the average values during treatment.

\begin{tabular}{|c|c|c|c|c|c|c|c|c|c|c|c|c|c|c|c|}
\hline \multirow{3}{*}{$\begin{array}{l}\text { No. } \\
\text { days }\end{array}$} & \multirow{3}{*}{ Treatment } & \multicolumn{4}{|c|}{$\begin{array}{c}\text { Nitrogen } \\
m g . / 24 \text { hrs. }\end{array}$} & \multicolumn{4}{|c|}{$\underset{m g . / 24 \text { hrs. }}{\text { Calcium }}$} & \multicolumn{4}{|c|}{$\begin{array}{l}\text { Phosphorus } \\
\text { mg. } / 24 \text { hrs. }\end{array}$} & \multirow{3}{*}{\multicolumn{2}{|c|}{ Theoretical P. balance }} \\
\hline & & \multirow{2}{*}{ Intake } & \multicolumn{2}{|c|}{ Output } & \multirow{2}{*}{ Balance } & \multirow{2}{*}{ Intake } & \multicolumn{2}{|c|}{ Output } & \multirow{2}{*}{ Balance } & \multirow{2}{*}{ Intake } & \multicolumn{2}{|c|}{ Output } & \multirow{2}{*}{ Balance } & & \\
\hline & & & Urine & Stool & & & Urine & Stool & & & Urine & Stool & & & \\
\hline 24 & None & 8480 & 8208 & 928 & -656 & 162 & 95 & 228 & -161 & 513 & 278 & 240 & -5 & $\begin{array}{l}\quad m g . / 24 \text { hrs. } \\
\text { Based on } \mathrm{N}_{2} \text { : } \\
\text { Based on } \mathrm{Ca} \text { : } \\
\text { Theoretical: } \\
\text { Actual } \\
\text { Unaccounted } \\
\text { retention: }\end{array}$ & $\begin{array}{r}-45 \\
-72 \\
-117 \\
-\quad 5 \\
+112\end{array}$ \\
\hline 24 & $\begin{array}{l}\text { Diethyl- } \\
\text { stilbes- } \\
\text { trol } 15 \\
\text { mg./day }\end{array}$ & 8588 & 8320 & 1013 & -745 & 176 & 36 & 199 & -59 & 556 & 245 & 252 & +59 & $\begin{array}{l}\text { Based on } \mathrm{N}_{2} \text { : } \\
\text { Based on } \mathrm{Ca} \text { : } \\
\text { Theoretical: } \\
\text { Actual: } \\
\text { Unaccounted } \\
\text { retention: }\end{array}$ & $\begin{array}{l}-51 \\
-26 \\
-77 \\
+59 \\
+136\end{array}$ \\
\hline 21 & $\begin{array}{l}\text { Diethyl- } \\
\text { stilbes- } \\
\text { trol 15 } \\
\text { mg./day }\end{array}$ & 9127 & 8480 & 1033 & -386 & 162 & 18 & 134 & +10 & 540 & 277 & 226 & +37 & $\begin{array}{l}\text { Based on } \mathrm{N}_{2} \text { : } \\
\text { Based on } \mathrm{Ca} \text { : } \\
\text { Theoretical: } \\
\text { Actual: } \\
\text { Unaccounted } \\
\text { retention: }\end{array}$ & 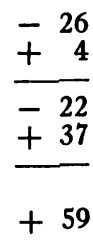 \\
\hline
\end{tabular}

Patient at home 44 days-Receiving Diethylstilbestrol $15 \mathrm{mg}$./day

\begin{tabular}{|c|c|c|c|c|c|c|c|c|c|c|c|c|c|c|c|}
\hline 30 & $\begin{array}{l}\text { Diethyl- } \\
\text { stilbes- } \\
\text { trol } 15 \\
\text { mg./day }\end{array}$ & 9166 & 8580 & 825 & -239 & 142 & 14 & 89 & +39 & 564 & 283 & 217 & +64 & $\begin{array}{l}\text { Based on } \mathrm{N}_{2} \text { : } \\
\text { Based on } \mathrm{Ca} \text { : } \\
\text { Theoretical: } \\
\text { Actual: } \\
\text { Unaccounted } \\
\text { retention: }\end{array}$ & 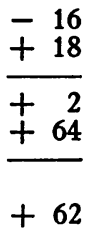 \\
\hline
\end{tabular}

\section{Pre-treatment phase (Periods 1-4)}

The acid phosphatase rose from 51 K.A.U. to a maximum of 199 units. The serum calcium, phosphorus and alkaline phosphatase remained within normal limits. The urinary calcium ranged from 85 to $120 \mathrm{mg}$. per day, representing about $25 \%$ of the total calcium excretion. The urinary phosphorus ranged from 197 to $341 \mathrm{mg}$. per day, representing about $54 \%$ of the total phosphorus excretion.

\section{Initial phase of treatment (Periods 5-11)}

No changes were noted initially in the urinary or fecal nitrogen excretion. The urinary calcium, however, fell precipitously from $121 \mathrm{mg}$. per day before treatment (Period 4) to $69 \mathrm{mg}$. per day in the first six day period after treatment was instituted (Period 5), to $34 \mathrm{mg}$. in the following period (Period 6), to $22 \mathrm{mg}$. in the next period (Period 7), and reached a value of $18 \mathrm{mg}$. per day in the succeeding period (Period 8 ). The stool calcium decreased at a much slower rate. The urinary and stool phosphorus changed very little.

The serum acid phosphatase dropped during the first period of therapy and decreased continuously to a value of $13.6 \mathrm{~K}$.A.U. in the fifth period of therapy (Period 9). Concomitantly with the decrease in the urinary calcium and serum acid phos- 
phatase, the serum alkaline phosphatase increased gradually to a maximum of $9.1 \mathrm{~B} . \mathrm{U}$. in the fifth period of therapy. The serum calcium decreased to a low of $7.8 \mathrm{mg}$. \%; the serum phosphorus showed no significant fluctuation.

\section{Later phase of treatment (Periods 12-16)}

Concomitant with the good general condition of the patient there were a decline and stabilization of the serum acid phosphatase around 6 K.A.U., of the serum alkaline phosphatase around 5 B.U., and of the urinary calcium around $15 \mathrm{mg}$. per day. In some of the later periods, the total calcium excretion (urinary and fecal) was less than the pre-treatment, urinary calcium excretion alone. Whereas the drop in urinary calcium was the most notable feature of the early phase of treatment, the decline of fecal calcium was the prominent feature of the later phase.

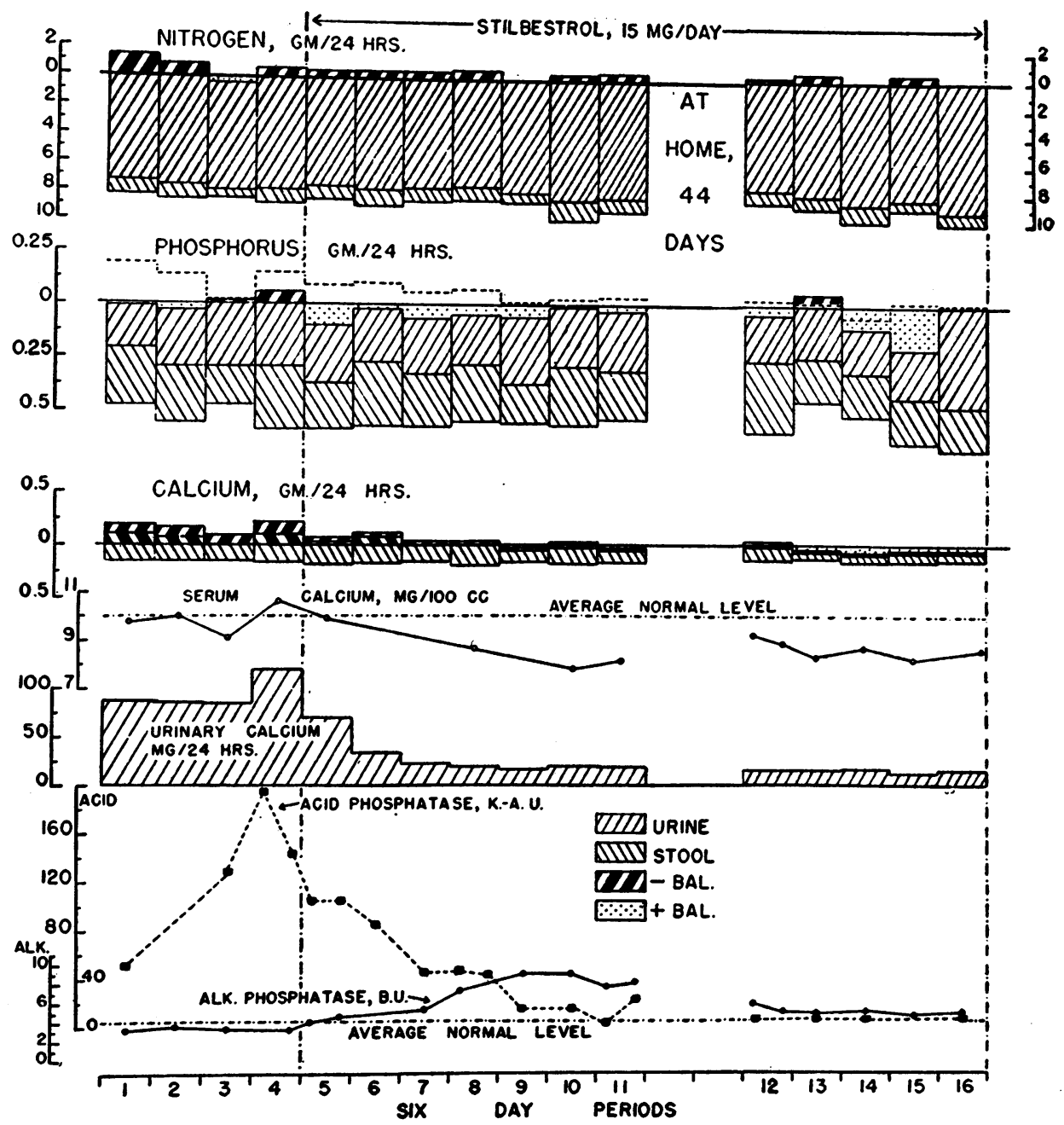

Fig. 2. Metabolic Graph Charted According to Reifenstein, Albright, and Wells (10)

The heavy horizontal line at zero in the nitrogen, phosphorus and calcium balance graphs indicates the equilibrium between intake and output. Intake is charted from the zero line downward. Output is charted from the intake line upwards toward the zero line. The lower hatched area represents fecal, and the hatched area above urinary excretion. The heavily shaded area above the zero line indicates negative balance; the dotted area below zero indicates positive balance. The interrupted lines in the phosphorus graph represent areas corresponding to the theoretical phosphorus retention or loss, calculated on the basis of theoretical $\mathrm{N}: \mathrm{P}$ and $\mathrm{Ca}: \mathrm{P}$ ratios (see text). One unit of the phosphorus scale equals 15 units of the nitrogen scale and 2 units of the calcium scale. 


\section{Metabolic balances (Table II)}

The nitrogen balance was somewhat negative in the pre-treatment phase, and it was only slightly influenced by therapy. The calcium balance, which was negative to the extent of $-161 \mathrm{mg}$. per day in the pre-treatment phase, improved to -59 in the first 24 days of treatment and became positive $(+39)$ in the later phase. The early improvement of the calcium balance was due mainly to the decline of the urinary calcium which dropped from $95 \mathrm{mg}$. to $36 \mathrm{mg}$. per day. Although the urinary calcium continued to drop in the later phase (36 to 14 mg.), the main factor in the later improvement of the calcium balance was the decline of the fecal calcium from $199 \mathrm{mg}$. to $89 \mathrm{mg}$. per day. The phosphorus balance changed little under therapy, from a slightly negative to a slightly positive balance.

The last 30 days of study represent the phase when the patient was in excellent general condition and had been on continuous estrogen therapy from 89 to 119 days. As previously noted, the acid and alkaline phosphatase values were only slightly above the normal during this phase. The patient was in a slightly negative nitrogen balance, but in a slightly positive calcium and phosphorus balance. The average urinary calcium was $14 \mathrm{mg}$. per day, about $1 / 7$ of the pre-treatment value. The stool calcium was $89 \mathrm{mg}$. per day, about $1 / 3$ of the pre-treatment value. About $14 \%$ of the total calcium excretion in this last phase is represented by urinary excretion, as contrasted to $25 \%$ before treatment. The urinary and fecal phosphorus did not show any major changes.

The theoretical phosphorus balance (10) (based on a nitrogen : phosphorus ratio of $15: 1$ and a calcium: phosphorus ratio of $2.2: 1$ ) was calculated for every period and indicated with a dotted line in Figure 2 and summarized in Table II. During the entire period of study, there was a phosphorus retention unaccounted for by the theoretical values based on the calcium and nitrogen balances. The amount of unaccounted phosphorus retention was less in the last two treatment phases than in the pre-treatment and first treatment phases.

\section{DISCUSSION}

In the following, the metabolic pattern of an untreated case of advanced prostatic carcinoma will be considered first, and the effect of estrogen therapy thereafter.

As indicated in the history, the total duration of the patient's symptoms before the study began was 14 months. The diagnosis was suspected six months after the onset of symptoms on the basis of a biopsy of a metastatic lesion. The treatment prior to this study consisted of radiotherapy to the pelvis and lumbar spine and of an inadequate trial of estrogen therapy. However, no treatment was given to the patient for a period of five months prior to this study. The clinical course at the beginning of metabolic studies was characterized by good nutritional status, slight anemia, moderate pain, diffuse osteoblastic metastases, marked elevation of serum acid phosphatase and a normal serum alkaline phosphatase. It is interesting to note that the urinary calcium excretion during the pre-treatment phase was moderately elevated and the calcium balance negative. This urinary calcium value is much lower than the values that we have observed in patients with a comparable amount of bone involvement of the predominantly osteolytic type (8). The calcium balance is much less negative in this patient than is seen in a patient with a predominantly osteolytic type of metastasis, such as metastatic breast carcinoma (8). In agreement with this is the observation of a normal serum calcium; whereas in cases of extensive osteolytic metastasis, hypercalcemia is not infrequently seen $(8,11,12)$. We have not observed a patient with a prostatic carcinoma exhibiting hypercalcemia, marked calcinuria, ectopic calcifications and renal stones.

The effect of estrogens upon the calcium, phosphorus and nitrogen metabolism of metabolic bone disease has been carefully studied and described by Gardner and Pfeiffer (13), Reifenstein and Albright $(14,15)$, and others. It has been noted that the effect of the estrogens on protein metabolism is less marked than the effect of androgens. The mode of action of estrogen in the therapy of prostatic cancer appears to be illustrated by this case. Whereas the nitrogen and phosphorus metabolism show initially only minor changes, a marked decline of urinary calcium during the first days of estrogen therapy is observed. At the height of estrogenic effect, the urinary calcium drops to subnormal values. A less marked and less rapid decline in fecal calcium accompanies the 
estrogenic effect. With the decline of urinary calcium, there is a decline of serum acid phosphatase and a slow, temporary, moderate rise of alkaline phosphatase. This latter phenomenon is interpreted by assuming that more calcium is being deposited in bone. An equilibrium appears to be reached at the height of benefit of estrogenic effect, when the serum acid phosphatase, and urinary and fecal calcium excretion are at the lowest, and when the alkaline phosphatase returns to its previous low value. The avidity of the tissues of such a patient for calcium is evidenced by the positive calcium balance on a low calcium intake under estrogen therapy.

A minimal beneficial effect of estrogen therapy on the nitrogen and phosphorus metabolism is observed.

\section{SUMMARY}

1. The effect of estrogen therapy upon the nitrogen, phosphorus and calcium metabolism of a patient with osseous metastases secondary to carcinoma of the prostate gland has been investigated. The clinical course has been correlated with the metabolic data.

2. The first manifestation of the estrogen effect was a decrease in the urinary calcium excretion together with a drop in serum acid phosphatase level, even preceding clinical improvement. A positive calcium balance on a low calcium diet was achieved by estrogen therapy, due to the decline in urinary calcium excretion initially and a decline in fecal calcium excretion in the later phase of treatment.

3. No marked changes of nitrogen and phosphorus metabolism were found.

4. The significance of these findings has been discussed.

\section{BIBLIOGRAPHY}

1. Nesbit, R. M., and Plumb, R. T., Prostatic carcinoma ; follow up on 795 patients treated prior to endocrine era and comparison of survival rates between these and patients treated by endrocrine therapy. Surgery, 1946, 20, 263.

2. Gutman, E. B., Sproul, E. E., and Gutman, A. B., Significance of increased phosphatase activity of bone at the site of osteoplastic metastases secondary to carcinoma of the prostate gland. Am. J. Cancer, 1936, 28, 485.

3. Huggins, C., Masina, M. H., Eichelberger, L., and Wharton, J. D., Quantitative studies of the prostatic secretion; I. Characteristics of the normal secretion; the influence of thyroid, suprarenal, and testis extirpation and androgen substitution on the prostatic output. J. Exper. Med., 1939, 70, 543.

4. Huggins, C., and Clark, P. J., Quantitative studies of prostatic secretion; II. The effect of castration and of estrogen injection on the normal and on the hyperplastic prostate glands of dogs. J. Exper. Med., 1940, 72, 747.

5. Huggins, C., and Hodges, C. V., Studies on prostatic cancer; I. The effect of castration, of estrogen and of androgen injection on the serum phosphatases in metastatic carcinoma of the prostate. Cancer Research, 1941, 1, 293.

6. Dean, A. L., Woodard, H. Q., and Twombly, G. H., The endocrine treatment of cancers of the prostate gland. Surgery, 1944, 16, 169.

7. Woodard, H. Q., and Dean, A. L., The significance of phosphatase findings in carcinoma of the prostate. J. Urol., 1947, 57, 158.

8. Laszlo, D., Schulman, C., Bellin, J., Gottesman, E. D., and Schilling, A., Breast carcinoma, a clinical and metabolic study. (In preparation).

9. Bauer, W., and Aub, J. C., Studies of inorganic salt metabolism; I. The ward routine and methods. J. Am. Dietet. A., 1927, 3, 106 .

10. Reifenstein, E. C., Jr., Albright, F., and Wells, S. L., The accumulation, interpretation, and presentation of data pertaining to metabolic balances, notably those of calcium, phosphorus, and nitrogen. J. Clin. Endocrinol., 1945, 5, 367.

11. Swyer, A. J., Berger, J. S., Gordon, H. M., and Laszlo, D., Hypercalcemia in osteolytic metastatic cancer of the breast. Am. J. Med., 1950, 7, 724.

12. Hermann, J. B., Kirsten, E., and Krakauer, J. S., Hypercalcemic syndrome associated with androgenic and estrogenic therapy. J. Clin. Endocrinol., 1949, 9, 1.

13. Gardner, W. U., and Pfeiffer, C. A., Influence of estrogens and androgens on the skeletal system. Physiol. Rev., 1943, 23, 139.

14. Reifenstein, E. C., Jr., and Albright, F., The metabolic effects of steroid hormones in osteoporosis. J. Clin. Invest., 1947, 26, 24.

15. Albright, F., and Reifenstein, E. C., Jr., Parathyroid Glands and Metabolic Bone Diseases; Selective Studies. Williams \& Wilkins Co., Baltimore, 1948.

16. Aub, J. C., Tibbets, D. M., and Nathanson, I. T., Metabolic effects of treatment of carcinoma of the prostate. Cancer Research, 1947, 7, 723. 